\title{
LEHRBÜCHER
}

DES

\author{
SEMINARS
}

FÜR

(9):RIENTALISCHE S:PRACHEN

\author{
ZU BERLIN
}

HERAUSGEGEBEN

VON DEM DIRECTOR DES SEMINARS

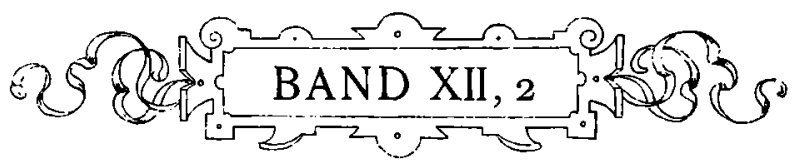

STUTTGART \& BERLIN

W. SPEMANN

1894 



\section{DEM ANDENKEN}

IHRER HOCHSELIGEN MAJESTÄT

DER

KAISERIN UND KÖNIGIN AUGUSTA

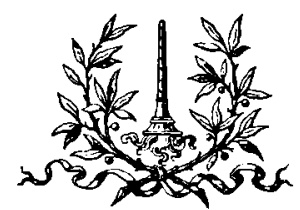





\section{XII}

\section{EINFÜHRUNG}

IN DIE

\section{N O R D C H I N E S I S C H E \\ UMGANGSSPRACHE}

PRAKTISCHES ÜBUNGSBUCH

ZUNÄCHST ALS GRUNDLAGE FÜR DEN UNTERRICHT AM SEMINAR VON

Prof. Carl Arendt

LEHRER DES CHINESISCHEN AM SEMINAR

\section{ABTHEILUNG}

CHINESISCHER TEXT DER ÜBUNGSBEISPIELE

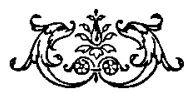

STUTTGART \& BERLIN

W. SPEMANN 




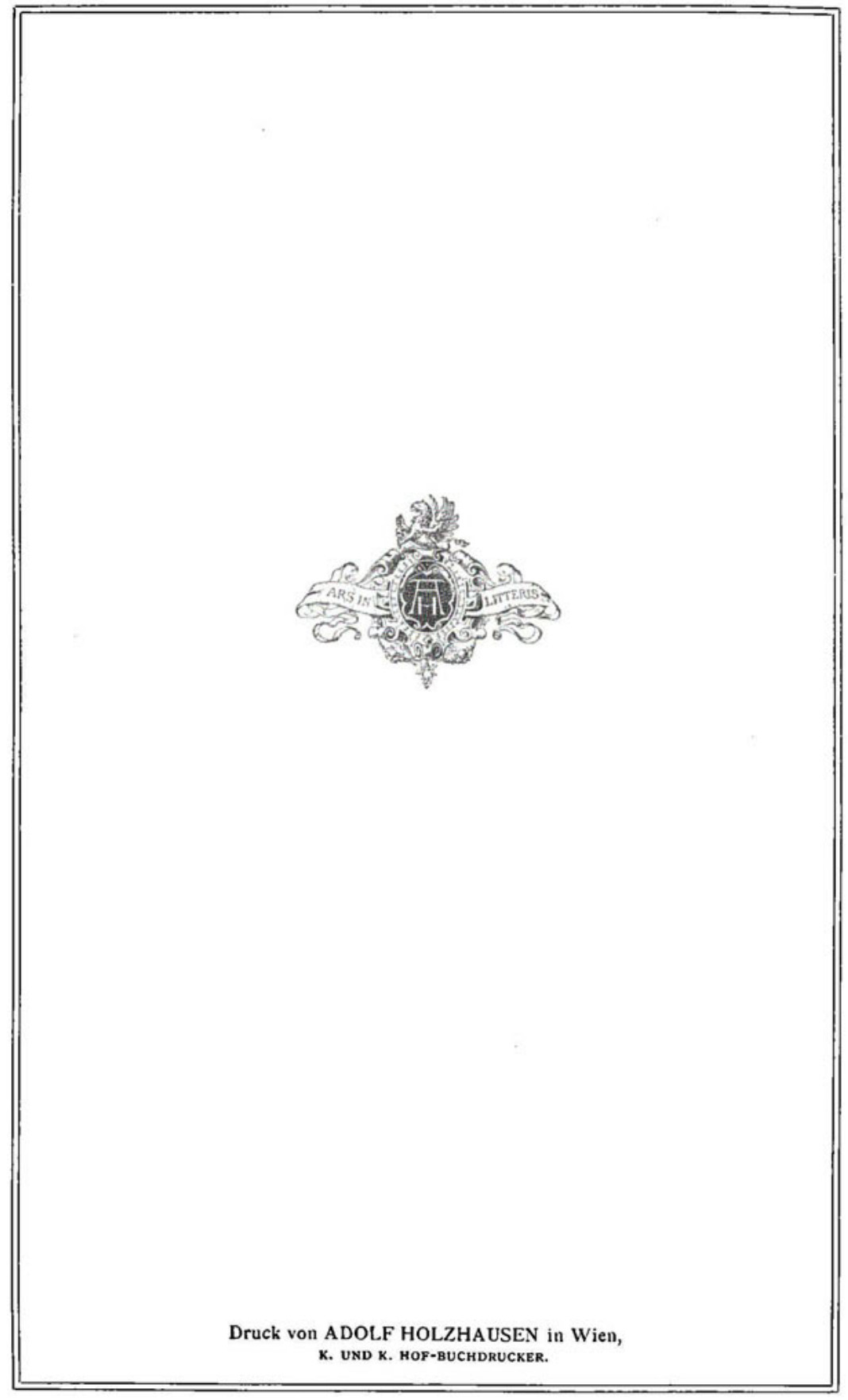

